\title{
Brain evoked potentials reflect how emotional faces influence our decision making.
}

Citation for published version (APA):

Steffen, A. C., Rockstroh, B., \& Jansma-Schmitt, B. M. (2009). Brain evoked potentials reflect how emotional faces influence our decision making. Journal of neuroscience, psychology, and economics, 2(2), 32-40. https://doi.org/10.1037/a0015464

Document status and date:

Published: 01/01/2009

DOI:

10.1037/a0015464

Document Version:

Publisher's PDF, also known as Version of record

Document license:

Taverne

Please check the document version of this publication:

- A submitted manuscript is the version of the article upon submission and before peer-review. There can be important differences between the submitted version and the official published version of record.

People interested in the research are advised to contact the author for the final version of the publication, or visit the DOI to the publisher's website.

- The final author version and the galley proof are versions of the publication after peer review.

- The final published version features the final layout of the paper including the volume, issue and page numbers.

Link to publication

\footnotetext{
General rights rights.

- You may freely distribute the URL identifying the publication in the public portal. please follow below link for the End User Agreement:

www.umlib.nl/taverne-license

Take down policy

If you believe that this document breaches copyright please contact us at:

repository@maastrichtuniversity.nl

providing details and we will investigate your claim.
}

Copyright and moral rights for the publications made accessible in the public portal are retained by the authors and/or other copyright owners and it is a condition of accessing publications that users recognise and abide by the legal requirements associated with these

- Users may download and print one copy of any publication from the public portal for the purpose of private study or research.

- You may not further distribute the material or use it for any profit-making activity or commercial gain

If the publication is distributed under the terms of Article $25 \mathrm{fa}$ of the Dutch Copyright Act, indicated by the "Taverne" license above, 


\section{Brain Evoked Potentials Reflect How Emotional Faces Influence Our Decision Making}

Article in Journal of Neuroscience Psychology and Economics · May 2009

DOI: 10.1037/a0015464 · Source: OAI

CITATIONS

13

3 authors, including:

Brigitte S Rockstroh

Universität Konstanz

316 PUBLICATIONS 16,530 CITATIONS

SEE PROFILE
Bernadette M Jansma

Maastricht University

73 PUBLICATIONS 1,869 CITATIONS

SEE PROFILE

Some of the authors of this publication are also working on these related projects:

GRIDSIGNALS View project

Dyslexia and the brain View project 


\title{
Brain Evoked Potentials Reflect How Emotional Faces Influence Our Decision Making
}

\author{
Astrid Christine Steffen \\ and Brigitte Rockstroh \\ University of Konstanz
}

\author{
Bernadette Jansma \\ Maastricht University
}

\begin{abstract}
Emotion is usually not discussed as a relevant variable in rational models of decision making - but may be one. The present electroencephalographic study demonstrates the influence of emotional primes (angry, happy faces) on purchase decisions. In a within-subject design, pictures of an apartment were shown to participants who then had to make Go/NoGo decisions on whether to rent it. Their decision should be based either on its price or on its brightness. In two thirds of the trials, emotional prime pictures of happy versus unhappy faces preceded the purchase target (apartment); in one third of the trials no prime was given. Response certainty was evaluated by means of reaction times (RT) and peak amplitude of the event-related potential N200. Facial primes accelerated decisions (RT) irrespective of affective expression. Positive face primes elicited larger N200 amplitudes during purchase decision compared to negative ones. Price-based decisions were made faster and elicited larger N200 than brightnessbased decisions. These results support the cognitive-tuning model of decision making and validate the N200 as sensitive measure for the interplay of cognitive and affective aspects in decision making.
\end{abstract}

Keywords: decision making, affective priming, N200, cognitive tuning, ERP

On daily basis we have to decide whether to buy a product or not. The decision relies on our perceived need (do I like it, is it necessary for survival or comfort) and on available resources (do I have the money). So-called rational coherence models explain decision making without linking it to emotion, but to logic and statistical inference (e.g., Chew, Epstein, \& Segal, 1991; Friedman, 1953; Savage, 1950). In contrast, others used empirical research results as a basis for explaining decision making and developed nonnormative correspondence models to challenge these rational coherence models (cf. Mercer, 2005): From Tversky and Kahneman (1973) to Gigerenzer (1996), on to a huge body of empirical research from neuroscience, psychology, or behavioral economics available to-

Astrid Christine Steffen, Clinical Psychology \& Clinical Neurospsychology Department, and Brigitte Rockstroh, Department of Psychology, University of Konstanz; Bernadette Jansma, Cognitive Neuroscience Department, Maastricht University.

Correspondence concerning this article should be addressed to Astrid Christine Steffen, Clinical Psychology \& Clinical Neurospsychology, University of Konstanz, Germany. E-mail: Astrid.steffen@uni-konstanz.de day (e.g., Camerer, Loewenstein, \& Prelec, 2004; Gehring \& Willoughby, 2002; Knutson et al., 2007; for an overview, see Hammond, 1996), the view is strengthened that emotion does play a role in decision making. Bechara and Damasio (2005) even went further by stating that sound and rational decision making depended on prior accurate emotional processing.

One of the most salient sources for emotional processing is the face, since the information from other people's emotional facial expressions is evaluated instantaneously (Eastwood, Smile, \& Merikle, 2003; Gallese et al., 2004). Positive and negative emotional facial expressions are faster recognized than neutral ones (Carvajal et al., 2004), and positive emotions are more readily processed than negative ones: Reaction times for happy faces are faster than for negative faces because they are less ambiguous (Carvajal et al., 2004; Eastwood et al., 2003; Esteves \& Öhman, 1993; Leppänen \& Hietanen, 2004). Leppänen, Tenhunen, and Hietanen (2003) termed this phenomenon the happy face advantage. In general, responses to negative valence are slower as they capture attention (e.g., Hansen \& Hansen, 1988) and 
disrupt performance (Eastwood et al., 2003). This is particularly true for responses to angry facial expressions (Baumeister, Bratslavsky, Finenauer, \& Vohs, 2001; Johnston et al., 2001; Leppänen et al., 2003). In the present study, we aimed to combine research on human decision making with consumer behavior. More specifically, the influence of emotion on a purchase decision task was probed by presenting faces with angry or happy expressions as prime stimuli prior to such a decision.

Everyday decisions are modulated by different aspects such as relevance of the decision, or availability of information (e.g., Camerer et al., 2004; Gigerenzer, 1996). The speed of decision varies with certainty (e.g., Bechara et al., 2000; Bechara \& Damasio, 2005; Glimcher, 2003; Kahneman \& Tversky, 1979). A purchase decision varies with rational criteria or preference, the latter being more context dependent than the first. Our interest in this study focused on rather rational, cognitive decisions.

One category of rational decisions is the so called price-based decision, being salient and of high cognitive availability (e.g., Diller, 2000; Kotler, 2001; Tversky \& Kahneman, 1996): Usually, people react faster to a cheaper rather than to an expensive price (e.g., Sandholm, 1999; Simon, 1979). In contrast to such a common cognitive decision as the price-based decision, a less common one is brightness discrimination. Brightness concerns the perceived intensity of light coming from the image itself (Adelson, 2000). Usually, in brightness discrimination, people are biased toward and react faster to bright relative to dark items (Ratcliff, 2002). On this background, the present study explored certainty during price based (i.e., common cognitive decisions) and brightness based (i.e., less common cognitive) decisions.

A nonrational factor influencing decision making is affect. The perception of one's own affective state is one of several sources of information relevant in decision making ("affect as information" see Clore \& Palmer, in press; Schwarz \& Clore, 1996). The cognitive tuning hypothesis (Schwarz, 2002; Schwarz \& Clore, 1996) goes one step further and states that being confronted with negative cognitive modes, people show a narrowed focus of attention (Broadbent, 1971; Easterbrook, 1959), a higher level of spontaneous causal reasoning (e.g., Bohner, Bless, Schwarz, \& Strack, 1988), increased vig- ilance and bottom-up data-driven processing (Bless, 1997; Schwarz, 1990). In contrast, people in a positive cognitive mode rely on their usual routines and pre-existing knowledge structures, which have served them in the past (Bless, 1997; Schwarz, 1990).

The present study exploited a variation (see below) of the affective priming paradigm (Murphy \& Zajonc, 1993) to examine affective modulation of cognitive decisions. In their original version of this paradigm, Murphy and Zajonc used briefly presented affective stimuli to show how these stimuli change decisions. Thus, these researchers validated Zajonc's (1984) affective primacy hypothesis, which states that affect accelerates decision making. Their findings have been replicated in behavioral (e.g., with sad faces; Wong et al., 2003), as well as in eventrelated potential (ERP) studies with emotional facial primes (happy and angry faces; e.g., Werheid, Alpay, Jentzsch, \& Sommer, 2005).

Next to whether emotion can influence the decision making, it is also relevant to see how and when in the information processing this influence takes place. Here we used ERPs to study cortical processes during decision making at millisecond basis. This study concentrated in particular on the ERP-component N200, which is visible in $\mathrm{Go} / \mathrm{NoGo}$ tasks, and refers to a negative peak ( 1 to $4 \mu \mathrm{V})$ in the ERP at about 100 to $300 \mathrm{~ms}$ after stimulus presentation (e.g., Pfefferbaum, Ford, Weller, \& Kopell, 1985). The N200 peak amplitude is usually more negative for NoGo versus Go trails. The difference NoGo/Go is referred to as the N200 effect, and its maximum signals the moment in time (N200 latency) and certainty (N200 amplitude) of the participant's decision to respond or not. The peak amplitude of the N200 has been shown sensitive to task difficulty (Falkenstein, Hoormann, \& Hohnsbein, 1999; Kopp, Mattler, Goerty, \& Rist, 1996) and certainty of decision. Smaller N200 effects usually come along with high-false alarm rates, suggesting that uncertainty during decision making may correlate with weaker inhibition processing (Falkenstein et al., 1999). Functional MRI results (Casey et al., 1997) and source analysis of ERPs (Kiefer, Marzinzik, Weisbrod, Scherg, \& Spitzer, 1998) located the effects in the orbital frontal cortex.

In analogy to standard Go/NoGo tasks in perception and language (see, e.g., RodriguezFornells, Schmitt, Kutas, \& Münte, 2002; 
Sasaki \& Gemba, 1986; Schmitt, RodriguezFornells, Kutas, \& Münte, 2001; Thorpe, Fize, \& Marlot, 1996), but to measure emotional influence on rational decisions, we asked participants to carry out a simple Go/NoGo decision: They had to indicate via button press whether to rent (Go) or not to rent (NoGo) the respective apartment shown on a screen.

In addition, a modified affective priming paradigm was embedded in this Go/NoGo task: Prior to presenting the target picture of the apartment, an emotional face was presented in some of the trials. Priming effects as predicted by the affect-as-information approach (Clore et al., 1994; Schwarz, 1990) and the affect heuristic (Slovic, 2002) are expected to elicit framing effects on decision making. These effects reflect response tendencies as suggested by the cognitive tuning hypothesis (Schwarz, 2002; Schwarz $\&$ Clore, 1996). Affective priming was expected to modulate reaction times and on the N200, which were expected to confirm to Leppänen et al.'s (2003) the happy-face advantage.

Moreover, different modulations of reaction times and N200 were expected for the different types of decision making due to different processing - this being related to task difficulties and certainty while deciding. Thus, we hypothesized, that (a) primes augment negative peak amplitudes and prompt faster decisions following happy faces with more negative peak amplitudes compared to decisions following an angry prime; (b) responses were faster in the price-based decision, as the more common one, than in the brightness decision; and (c) more certainty in price-based decisions should increase peak amplitude of the N200-NoGo/Go effect relative to brightness-based decisions (e.g., Falkenstein, 1999).

\section{Method}

Twenty-one right-handed participants (15 women) mean age 21.2 years, range 17 to 32 years received financial or course credit bonus for participation. For sample selection, each participant filled in a screening form and sent it in via email. Prior to the experimental session each participant signed a written consent form, and filled in a checklist including use of medication, alcohol, drugs, brain damage, dyslexia, epilepsy, and concentration problems. Handedness was determined by a shortened version of the Edinburgh Handedness Inventory (Oldfield, 1971). Each participant received a debriefing form explaining the main objectives of the study after participating. Only healthy, right-handed participants with normal or corrected to normal vision were included.

\section{Design and Material}

The study design was approved by the ethical committee of the faculty of Psychology at Maastricht University via a "research line approval" to the division "cognitive neuroscience." Within a $2 \times 2 \times 3$ experimental repeated-measures design, the within-subject factors brightness (bright vs. dark), price (cheap vs. expensive) of apartments and affective prime (happy vs. angry faces vs. no prime).

Targets of decision were 48 pictures of apartments ( 24 bright, 24 dark, sized $304 \times 228$ pixels in landscape format). Prime stimuli were 48 pictures of faces ( 24 happy ones and 24 angry ones, sized $224 \times 288$ pixels in portrait format). Pictures of faces were taken from the standardized database of NimStim (http:// www.macbrain.org/faces/index.htm; Tottenham, Borscheid, Ellersten, Marcus, \& Nelson, 2002) and edited with Adobe Photoshop (pro CS2, Version 9) to use a 256-bit color palette. The distance between participants and monitor was arranged to meet $80 \mathrm{~cm}$, the extension in degrees of the visual angle was 11.3 in height and 6.4 in width for target stimuli and $6.3^{\circ}$ in height and of $4.6^{\circ}$ in width for prime stimuli. For the present experiment pictures were selected which participants during the NimStimvalidation process had rated as happy/angry at a reliability of $r=.80$ (or higher). Faces included different gender (15 female, 9 male faces) and ethnicity, and each face appeared with happy and with angry expression. Pictures of the apartments were photos assembled from the Internet and privately. Each photo showed an empty room with white walls and one to two corners, including one or two sources of light (windows or/and a lamp). Bright versions of room pictures were produced by adding brightness (to +50 using the "brightness" function of Adobe Photoshop Pro CS2 Version 9.0 for the bright experimental version) to the original picture; the original pictures then represented the dark examples. 


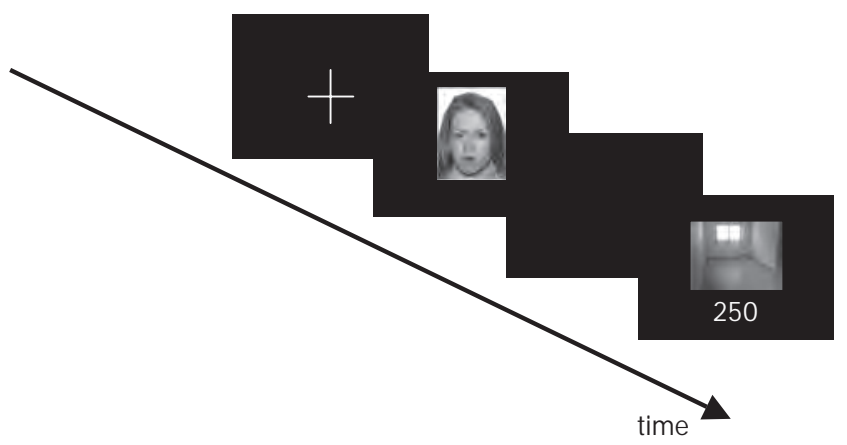

Figure 1. Illustration of one trial in a condition with prime preceding target stimulus. Participants see consecutively the following: (a) The fixation cross for 300 to $700 \mathrm{~ms}$ at random, (b) an affective prime (angry or happy face) for $200 \mathrm{~ms}$, (c) a mask for $50 \mathrm{~ms}$, (d) the target picture (dark or bright and expensive or cheap) of a room for 1,500 ms, and (e) clear screen for $800 \mathrm{~ms}$. In conditions without prime ("no prime condition"), there was no substitution for the 200-ms time window of prime presentation.

A price label of the monthly rent was added underneath each apartment picture (see Figure 1), and each apartment was presented once with price tag lower than local standards (" 250 Euro") and once with a higher price ("750 Euro"; written in Arial, 18 pt). Task instructions were presented on the screen in white on black (12 pt Arial). The experimental design was programmed using the Experimental Run Time System software (ERTS, Version V3.37b; Beringer, 1987), which also recorded reaction times and errors during data acquisition. A Dell PC was used (Optiplex GX206), participants saw the stimuli on a 17-inch screen (Dell, M782P, $70 \mathrm{~Hz}$, refresh rate $16 \mathrm{~ms}$ ). Participants indicated their decision by pressing the right "shift" key of a QWERTY keyboard. Response times were stored on computer hard disk. The experiment lasted for about $2.5 \mathrm{hr}$.

\section{Procedure}

On arriving at the electroencephalogram (EEG) laboratory, after introduction to the experiment including written consent and verifying handedness (see above), a 32-scalp electrode cap was fixed onto the participant's head, before she/he was led into a sound-proof, constant-dimly lit experimental chamber. Baseline trials familiarized the participant with stimulus categories (dark and bright flat version, without price). Repetition of the baseline trial series served to reduce learning effects and to measure
ERP with control for item effects. The experimental series consisted of eight blocks that covered the 12 experimental conditions.

Prior to each trial block, participants read task instructions: Whenever participants had to base their decision on brightness, the written instruction told them to rent (a) a bright apartment because otherwise they would suffer from severe tensions in the neck and headaches, or (b) to rent a dark flat because otherwise they would suffer from severe tensions in the neck and headaches. Prior to price-based decisions, participants read that they should save money by (c) not exceeding a certain budget (= cheap), or (d) exceeding a certain budget purposively because of tax-related reasons (= expensive).

Prior to trials including primes, participants were instructed that the task relevant picture (apartment) would be preceded by another picture, irrelevant for decision. Participants were requested to make a $\mathrm{Go} / \mathrm{NoGo}$ decision in response to each trial. Decisions to rent a apartment should be indicated by pressing a button; decisions not to rent the shown apartment should be indicated by suppressing the button press. Within the total 1,152 trials were four blocks without prime stimuli and four blocks of included 192 trials with affective primes (96 of which with happy and 96 with angry faces). Thus each condition comprised 96 target stimuli (24 pictures of dark rooms, 24 pictures of bright rooms, each being presented once with a low price and once with a high price). Each block 
was preceded by an additional 8 practice trials, not included in the analysis. The order of the eight blocks was counterbalanced across participants. Blocks were separated by breaks of variable length, which allowed participants to relax. A typical trial started with a 300 to $700 \mathrm{~ms}$ presentation of a fixation cross.

In trials without primes the fixation cross was immediately followed the 1.5-s target stimulus, the response keys were activated during this interval. With the offset of the target stimulus the screen turned black for $800 \mathrm{~ms}$. In trials with affective primes the fixation cross was followed by the $200-\mathrm{ms}$ presentation of prime; between prime and target $(1,500 \mathrm{~ms}$, with response keys activated) the screen went black for $50 \mathrm{~ms}$. Again target offset was followed by the black screen for $800 \mathrm{~ms}$.

\section{Data Analysis}

Dependent variables were reaction times (RT) and peak amplitude of the N200. RT and errors were analyzed in a $3 \times 2$ (prime, decision) repeated-measures analysis of variance (ANOVA) with SPSS 12.0.1. The EEG was recorded from 32 scalp electrodes located according to the extended 10/20 system (Jasper, 1958). Electrode impedance was kept below 5 $\mathrm{k} \Omega$ for all electrodes. The EEG signal was amplified with SynAmps and analyzed using NeuroScan 4.3 and SPSS software. EEG data were re-referenced offline to the average of the left and right mastoid signal. Data epochs of $800 \mathrm{~ms}$ prior to each target (target locked with a $100 \mathrm{~ms}$ prestimulus interval) were filtered with a bandpass zero phase shift filter of 0.05 to $30 \mathrm{~Hz}$ with a $24 \mathrm{~dB} /$ oct cut-off. The signal was baseline corrected and trials with eye movements were removed ( $75 \mu \mathrm{V}$ threshold) from further analyses. Across participants and trial blocks about $32 \%$ were rejected trials. Error trials (false alarms, misses) were excluded via a computer program. ERPs were determined only for trials with correct responses. Grand averages were calculated by taking the individual averages as a basis. After arcsin transforming the proportions (Winer, 1971) of rejected trials, differences between rejected and accepted trials per condition were evaluated by an ANOVA. A $3 \times 2 \times 2$ ANOVA with the factors prime, decision, and Go/NoGo indicated a higher number of rejected trials in the brightness condition $(40 \pm 18 \%)$

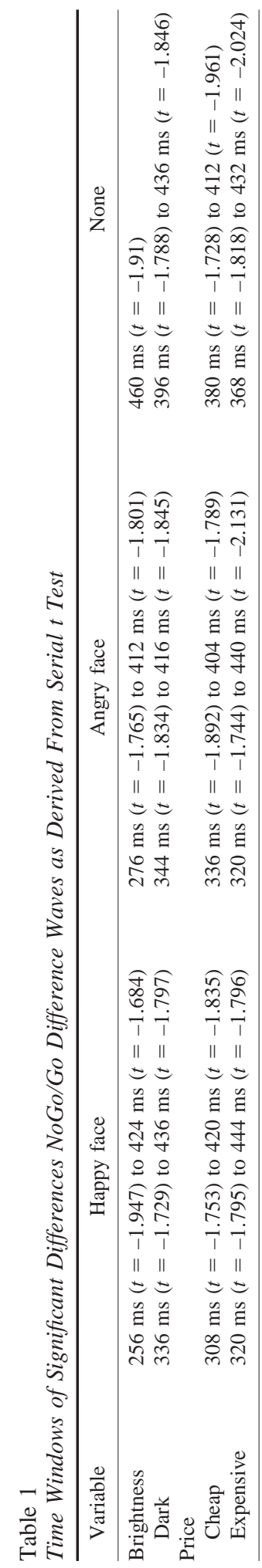


Table 2

Mean Reaction Times

\begin{tabular}{lccc}
\hline Variable & Happy face & Angry face & No prime \\
\hline Brightness & & & \\
Bright & 680 & 668 & 704 \\
Dark & 669 & 688 & 749 \\
Price & & & \\
Cheap & 556 & 548 & 582 \\
Expensive & 555 & 555 & 576 \\
\hline
\end{tabular}

Note. Reaction times given in milliseconds. Used was an analysis of variance with the factors Decision (brightness, price) $\times$ Brightness (bright, dark) $\times$ Price (cheap, expensive) $\times$ Prime (happy face, angry face, no prime).

than in the price condition $26 \pm 26 \%, F(1$, $20)=13.7, p<.01$. The time windows of the N200 effect was determined by (a) serial $t$ tests comparing Go/NoGo ERPs (see Table 1) and (b) serial paired $t$ tests comparing affective prime conditions (happy, angry, no prime) and between decision conditions (price, decision), and (c) visual inspection to identify the effect individually.

NoGo-N200 was significantly more negative than Go-N200 in all experimental conditions, confirming the N200 effect was continued by more negative NoGo-N200 than Go-N200. The effect was most pronounced at $\mathrm{AFz}$ so that result will be reported for this electrode site.

\section{Results}

As summarized in Table 2, RT was $693 \pm$ $117 \mathrm{~ms}$ on brightness decision and $562 \pm 124$ $\mathrm{ms}$ on price decision. RT on trials without primes were $653 \pm 110 \mathrm{~ms}$, and on trials with primes $615 \pm 123 \mathrm{~ms}$. The impact of target was confirmed by a main effect target, $F(1$, $20)=9.70, p<.01$ : Participants were faster by $131 \mathrm{~ms}$ on price-based decisions than on brightness-based decisions. The impact of prime was confirmed by a main effect prime, $F(2$, $19)=9.26, p<.01$ : Participants were about 38 ms faster in conditions with prime than without prime. RT did not differ significantly between the two prime conditions (happy vs. angry face, $p>$ .05). Participants made fewer errors in price-based decisions $(5 \pm 14 \%)$ than in brightness-based decision $(33 \pm 21 \%) F(1,20)=72.89, p<.01$. Thus, brightness-based decisions seemed to be more difficult than price-based decisions.
The N200 effect was more pronounced on price-based decision $(-5.35 \pm 2.9 \mu \mathrm{V})$ than for the brightness-based decision $(-3.64 \pm 2.0$ $\mu \mathrm{V}) F(1,20)=10.38, p<.01$. Figures 2 and 3 illustrate the N200 in the different conditions. Planned pairwise comparisons confirmed significant differences between the dark and the expensive condition (1.81 with $S E=0.78, p=$ .032). Happy faces evoked larger peak amplitude $(-5.32 \pm 3.1 \mu \mathrm{V})$ than angry faces $(-4.48 \pm 2.2 \mu \mathrm{V})$ and no prime $(-3.69 \pm 1.9$ $\mu \mathrm{V}) F(2,19)=4.558, p<.05$. Figure 4 gives an overview of significant differences between the mean N200 peak amplitudes per condition.

\section{Discussion}

The present study shows that ERPs add to RTs in the evaluation of decision making and allow evaluating ongoing brain processes, while decision making under affective influences takes place.

Whereas RT analysis revealed a global priming effect, ERPs fine tuned the results and further showed that also affective context-inducing primes influence decisions. A happy-face advantage was found for N200 peak amplitude indicating that each affective prime boosts response certainty, but the positive prime was

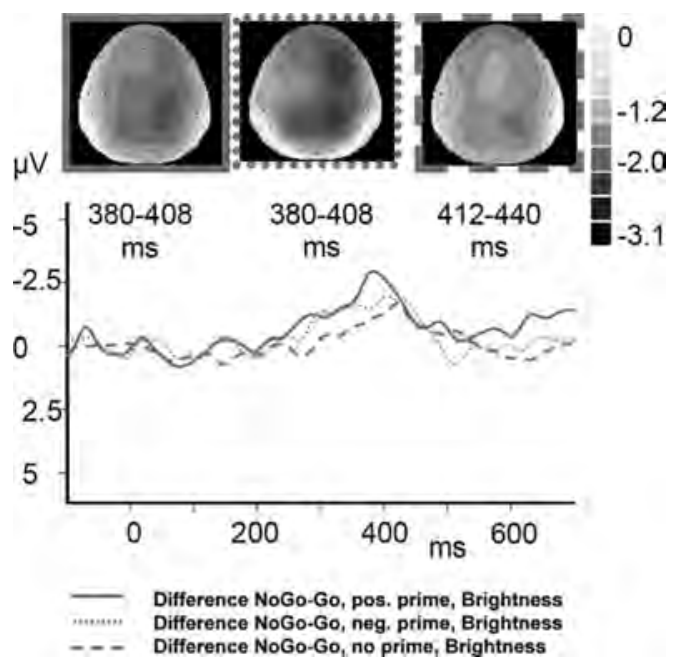

Figure 2. Topographic maps for NoGo/Go difference per prime in the brightness-based decision, taken from the time window of maximal activity. The whole distributions of the NoGo-Go difference waves are depicted below the topographic maps [electrode: AFz]. 


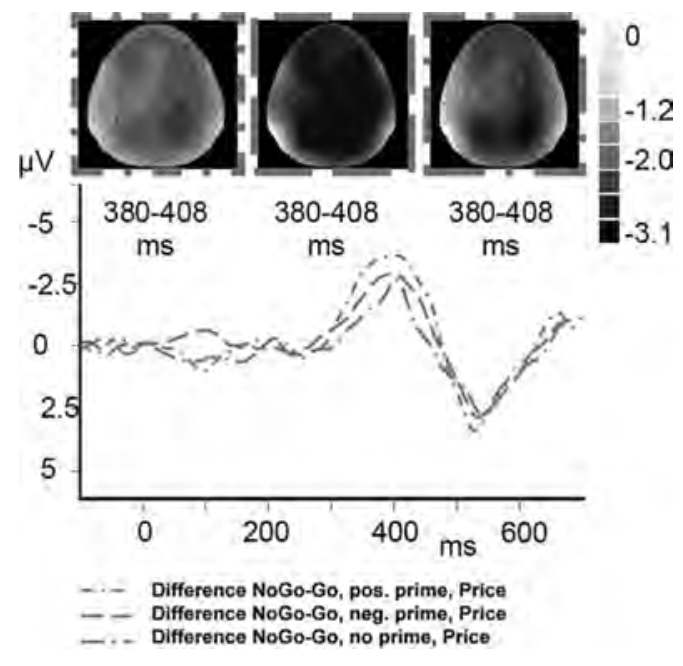

Figure 3. Topographic maps for NoGo/Go difference per prime in the price-based decision, taken from the time window of maximal activity. The whole distributions of the NoGo/Go difference waves are depicted below the topographic maps [electrode: $\mathrm{AFz}$ ].

particularly effective. We may conclude that individuals were more certain in their decision making after seeing a happy face as compared to an angry face. These results confirm the cognitive tuning hypothesis exploiting the cortical response measure N200. Moreover, results also confirm the "affect-as-information" hypothesis: Decision certainty was facilitated in the context of a prime, relative to decisions without any prime.

As expected, the seemingly more difficult brightness decision required more time and was processed with less certainty than the more common, unambiguous price decision. Independent from affective influences, the type of decision modulates speed and certainty of decision.

Task difficulty was reflected in the peak amplitude N200-NoGo/Go effect: Participants were least certain when choosing a dark apartment and most certain when deciding for an expensive apartment.

In contrast to our expectation neither RTs and errors nor N200 peak amplitude disclosed an interaction of affective prime and type of decision. This suggests that affect influences decision independently from type or task difficulty of decision.
Weaknesses of the study should be considered: In addition to the no prime control a control condition for the main effect of affective manipulation with "neutral" stimuli (low arousal, no specific valence) could have been expected within the present study. A neutral face condition was impaired (and discarded) by the fact that it is more difficult to find truly "neutral" facial expressions, which do not convey emotional information. In contrast the NimStim Face Set (Tottenham et al., 2002) assures reliability ( $r=.80$ or higher) and that elicited arousal was kept constant to ensure the modulatory impact of the valence component. Murphy and Zajonc (1993) did not find significant differences between neutral face and no prime control conditions or between task irrelevant and no prime conditions.

The present results are in line with recent neuroeconomic fMRI studies: Knutson, Rick, Wimmer, Prelec, and Loewenstein (2007) published a neuroeconomic study that is thematically related, but they used preference judgments in an event-related fMRI study to reveal "neural predictors of purchase," and to investigate how people weigh the factors of consumer preference and price to make purchasing decisions in a Go/NoGo task. These authors concluded activation of distinct neural circuits related to anticipatory affect that preceded consumers' purchasing decisions.

In sum, the present study provides the first detailed ERP support for cognitive tuning effects on decision making-more specifically on

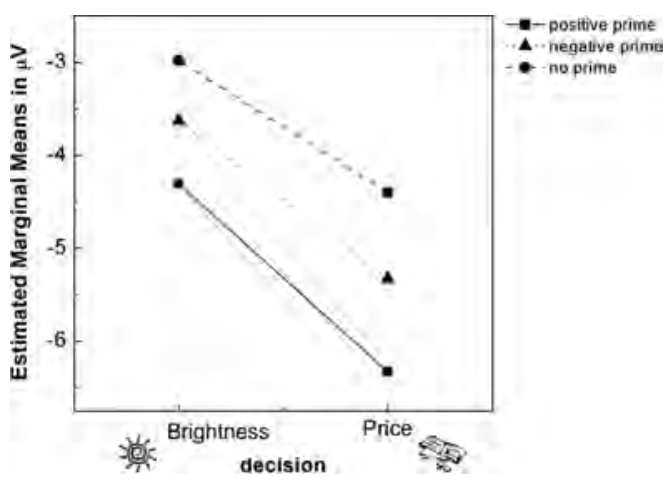

Figure 4. Significant differences between the marginal means of the peak amplitude. Results from an analysis of variance (ANOVA) with the factors Decision (brightness, price) $\times$ Prime (positive, negative no prime). 
decision making in the context of purchasing. Emotions that are seemingly irrelevant for a correct decision influenced the decision making process. As other people's emotions are processed quickly and influence subsequent responses or decisions, participants of the present study were affected by facial primes confirming assumptions from the affect-as-information approach. Regarding rational choice models, it can be concluded that, it should not be neglected that human beings are social beings when modeling human decision making. Emotion is the most salient social information. Thus, "emotion" is a type of information, which is also important during efficient decision making.

\section{References}

Adelson, E. H. (2000). Lightness perception and lightness illusions. The New Cognitive Neuroscience, 2, 339-351.

Baumeister, R. F., Bratslavsky, E., Finkenauer, C., \& Vohs, K. D. (2001). Bad is stronger than good. Review of General Psychology, 5, 323-370.

Bechara, A., \& Damasio, A. R. (2005). The somatic marker hypothesis: A neural theory of economic decision. Games and Economic Behavior, 52, 336-372.

Bechara, A., Tranel, D., \& Damasio, H. (2000). Characterization of the decision-making deficit of patients with ventromedial prefrontal cortex lesions. Brain, 123, 2189-2202.

Beringer, J. (1987). Experimental Run Time System. 3.32c. Frankfurt: Berisoft Corporation.

Bless, H. (1997). Stimmung und Denken [Mood and reasoning]. Bern, Switzerland: Huber.

Bohner, G. Bless, H., Schwarz, N., \& Strack, F. (1988). What triggers causal attributions? The impact of valence and subjective probability. European Journal of Social Psychology, 18, 335-345.

Broadbent, D. E. (1971). Decision and stress. London: Academic.

Camerer, C. F., Loewenstein, G., \& Prelec, D. (2004). Neuroeconomics: Why economics needs brains. Scandinavian Journal of Economics, 106, 555-579.

Carjaval, F., Vidriales, R., Rubio, S., \& Martín, P. (2004). Effect of the changes in facial expression and/or identity of the model on a face discrimination task. Psicothema, 16, 587-591.

Casey, B. J., Trainor, R. J., Orendi, J. L., Schubert, A. B., Nystrom, L. E., Giedd, J. N., et al. (1997). A developmental functional MRI study of prefrontal activation during performance of a Go-noGo task. Journal of Cognitive Neuroscience, 9, 835-847.
Chew, S. H., Epstein, L. G., \& Segal, U. (1991). Mixture symmetry and quadratic utility. Econometrica, 59, 139-163.

Clore, G., Clore, G. L., \& Palmer, J. (2009). Affective guidance of intelligent agents: How emotion controls cognition. Cognitive Systems Research, 10, 21-30.

Clore, G. L., Schwarz, N., \& Conway, M. (1994). Affective causes and consequences of social information processing. In R. S. Wyer \& T. Srull (Eds.), The handbook of social cognition (Vol. 2, pp. 323-417). Mahwah, NJ: Erlbaum.

Diller, H. (2000). Preispolitik [Price strategy] (Vol. 3). Stuttgart, Germany: Kohlhammer.

Easterbrook, J. A. (1959). The effect of emotion on cue utilization and the organization of behavior. Psychological Review, 66, 183-201.

Eastwood, J. D., Smilek, D., \& Merikle, P. M. (2003). Negative facial expression captures attention and disrupts performance. Perception and Psychophysics, 65, 352-358.

Esteves, E., \& Öhman, A. (1993). Masking the face: Recognition of emotional facial expressions as a function of the parameters of backward masking. Scandinavian Journal of Psychology, 34, 1-18.

Falkenstein, M., Hoormann, J., \& Hohnsbein, J. (1999). ERP components in Go Nogo tasks and their relation to inhibition. Acta Psychologica, 101, 267-291.

Friedman, M. (1953). The methodology of positive economics. In M. Friedman (Ed.), Essays in positive economics (pp. 3-43). Chicago: Chicago University Press.

Gallese, V., Keysers, C., \& Rizzolatti, G. (2004). A unifying of the basis of social cognition. Trends in Cognitive Sciences, 8, 396-403.

Gehring, W. J., \& Willoughby, A. R. (2002). The medial frontal cortex and the rapid processing of monetary gains and losses. Science 295, 2279-2282.

Gigerenzer, G. (1996). On narrow norms and vague heuristics: A reply to Kahneman and Tversky (1996). Psychological Review, 103, 592-596.

Glimcher, P. W. (2003). Decisions, uncertainty and the brain: The science of neuroscience. Cambridge: Bradford Books.

Hammond, K. R. (1996). Human judgment and social policy: Irreducible uncertainty, inevitable error, unavoidable injustice. New York: Oxford University Press.

Hansen, C. H., \& Hansen, R. D. (1988). Finding the face in the crowd: An anger superiority effect. Journal of Personality and Social Psychology, 54, 917-924.

Jasper, H. H. (1958). The ten-twenty system of the international federation. Electroencephalography and Clinical Neurophysiology, 10, 371-375.

Johnston, P. J., Katsikitis, M., \& Carr, V. J. (2001). A generalized deficit can account for problems in 
facial emotion recognition in schizophrenia. Biological Psychology, 58, 203-227.

Kahneman, D., \& Tversky, A. (1979) Prospect theory: An analysis of decision under risk. Econometrica, 47, 263-291.

Kiefer, M., Marzinzik, F., Weisbrod, M., Scherg, M., \& Spitzer, M. (1998). The time course of brain activations during response inhibition: Evidence from event-related potentials in a go/no go task. NeuroReport, 9, 765-770.

Knutson, B., Rick, S., Wimmer, G. E., Prelec, D., \& Loewenstein, G. (2007). Neural predictors of purchases. Neuron, 53, 147-156.

Kopp, B., Mattler, U., Goerty, R., \& Rist, F. (1996). N2, P3 and the lateralized readiness potential in a nogo task involving selective response priming. Electroencephalography and Clinical Neurophysiology, 99, 19-27.

Kotler, P. (2001). A framework for marketing management. Upper Saddle River, NJ: Prentice Hall.

Leppänen, J. M., \& Hietanen, J. K. (2004). Positive facial expressions are recognized faster than negative facial expressions, but why? Psychological Research, 69, 22-29.

Leppänen, J. M., Tenhunen, M., \& Hietanen, J. K. (2003). Faster choice-reaction times to positive than to negative facial expressions. Journal of Psychophysiology, 17, 113-123.

Mercer, J. (2005). Rationality and psychology in international politics. International Organization, 59, 77-106.

Murphy, S. T., \& Zajonc, R. B. (1993). Affect, cognition, and awareness: affective priming with optimal and suboptimal stimulus exposures. Journal of Personality and Social Psychology, 64, 723-739.

Oldfield, R. C. (1971). The assessment and analysis of handedness: The Edinburgh inventory. Neuropsychologia, 9, 97-113.

Pfefferbaum, A., Ford, J., Weller, B., \& Kopell, B. (1985). ERPs to response production and inhibition. Electroencephalography and Clinical Neurophysiology, 60, 423-434.

Ratcliff, R. (2002). A diffusion model account of response time and accuracy in a brightness discrimination task: Fitting real data and failing to fit fake but plausible data. Psychonomic Bulletin and Review, 9, 278-291.

Rodriguez-Fornells, A., Schmitt, B. M., Kutas, M., \& Münte, T. F. (2002). Electrophysiological estimates of the time course of semantic and phonological encoding during listening and naming. Neuropsychologica, 40, 778-787.

Sandholm, T. W. (1999). Distributed rational decision making. In G. Wei $\beta$ (Ed.), Multiagent systems (pp. 201-224). Cambridge, MA: MIT Press.

Sasaki, K., \& Gemba, H. (1986). Electrical activity in the prefrontal cortex specific to noGo reaction of conditioned hand movement with color discrimi- nation in the monkey. Experimental Brain Research, 64, 603-606.

Savage, L. J. (1950). The role of personal probability in statistics. Econometrica, 18, 183-184.

Schmitt, B. M., Rodriguez-Fornells, A., Kutas, M., \& Münte, T. F. (2001). Rapid communication: Electrophysiological estimates of semantic and syntactic information access during tacit picture naming and listening to words. Neuroscience Research, 41, 293-298.

Schwarz, N. (1990). Feelings as information: Informational and motivational functions of affective states. E. T. Higgins \& R. Sorrentino (Eds.), Handbook of motivation and cognition: Foundations of social behavior (Vol. 2, pp. 527-561). New York: Guilford.

Schwarz, N. (2002). Situated cognition and the wisdom of feelings: Cognitive tuning. In L. Feldman Barrett \& P. Salovey (Eds.), The wisdom in feelings (pp. 144-166). New York: Guilford.

Schwarz, N., \& Clore, G. L. (1996). Feelings and phenomenal experiences. In E. T. Higgins \& A. Kruglanski (Eds.), Social psychology: A handbook of basic principle (pp. 433-465). New York: Guilford.

Simon, H. A. (1979). Rational decision making in business organizations. American Economic Review 69, 493-513.

Slovic, P., Finucane, M., Peters, E., \& MacGregor, E. D. (2002). Rational actors or rational fools: Implications of the affect heuristic for behavioral economics. Journal of Socio-Economics, 32, 329342.

Thorpe, S., Fize, D., \& Marlot, C. (1996) Speed of processing in the human visual system. Nature, 381, 520-522.

Tottenham, N., Borscheid, A., Ellertsen, K., Marcus, D. J., \& Nelson, C. A. (2002). The NimStim Face Set. Retrieved October 2006, from http://www.macbrain.org/faces/index.htm, or via Nim Tottenham at tott0006@tc.umn.edu. Developed in cooperation with the John D. and Catherine T. MacArthur Foundation Research Network on Early Experience and Brain Development.

Tversky, A., \& Kahneman, D. (1973). Availability: A heuristic for judging frequency and probability. Cognitive Psychology, 5, 207-232.

Werheid, K., Alpay, G., Jentzsch, I., \& Sommer, W. (2005). Priming emotional facial expressions as evidenced by event-related brain potentials. International Journal of Psychophysiology, 55, 209-219.

Winer, B. J. (1971). Statistical principles in experimental design (3rd ed.). New York: McGraw Hill.

Wong, P. S., \& Root, J. C. (2003). Dynamic variations in affective priming. Consciousness and Cognition, 12, 147-168.

Zajonc, R. B. (1984). On the primacy of affect. American Psychologist, 39, 117-124. 